\title{
Automatic Generation Control of Two Area Power System with Hybrid Control Technique
}

\author{
${ }^{*}$ Smt. Muppoori Nagendra ${ }^{1}$, Mr. M. Suresh Babu² Dr. P. Sampath Kumar ${ }^{3}$ \\ ${ }^{123}$ Assistant Professor, Department of Electrical and Electronics Engineering \\ Bapatla Engineering College (Autonomous), Bapatla, Guntur (Dt), AP,INDIA.
}

\begin{abstract}
In this paper dynamic performance of Automatic Generation Control (AGC) for two area power system with conventional PID and Fuzzy PID controller with different load disturbance and for different systems is presented. AGC plays an important role in multi area power system to maintain system frequency and tie-line powers at their normal values. The performance analysis of AGC for two area power system done in MATLAB/SIMULINK environment. The simulation results show that the Fuzzy-PID controller gives improved dynamic performance of system compared to conventional PID controller.
\end{abstract}

Keywords: Automatic Generation Control, Load Frequency Control, Proportional Integral Derivative Controlling Techniques, Fuzzy Logic Controller, Tie Line Power, Settling Time, Peak Over Shoot, Fuzzy - PID.

\section{INTRODUCTION}

Power systems consist of control areas representing a coherent group of generators. These control areas are interconnected through tie-lines for providing exchange of power and to eliminate mismatch between generation and demand in addition to their own generations under normal operating conditions. Due to sudden disturbances or some other reasons if the generated active power less than the actual power demand the frequency of generating units tends to decreases. This causes system frequency deviates from its nominal value which is undesirable. To damp out frequency deviation and to keep tie line power at its scheduled value Automatic Generation Control is used. Automatic generation control (AGC), is a major control function within a utility's energy control centre, for tracking load variations while maintaining system frequency, net tie-line interchanges, and optimal generation levels close to scheduled values. The reason to keep system frequency constant is speed of ac motors are directly related to frequency, steam and hydro turbine blades are gets damaged if frequency variations are large and also operation of transformer below rated frequency is not desirable. The AGC loop continuously regulates the active power output of the generator to match with the randomly varying load.

In order to improve stability and performance of AGC, a very fast accurate and robust controller is required to maintain system nominal frequency. The well-known proportional-integral-derivative (PID) controllers are still widely employed in industrial process control though many control theories have been developed. The popularity of a PID controller is due to its good performance and functional simplicity [1]-[4]. The disadvantage of the conventional controllers are they exhibit poor dynamic performance especially in the presence of parameter variations, Loading conditions and nonlinearities. So it is required a flexible controller to improve the performance of the system under these conditions. Artificial intelligence techniques such using algorithms like fuzzy logic [7], [8], [9] [10], Artificial Neural Networks (ANN) [5], Hybrid Fuzzy ANN [6] to improve dynamic performance of system under such conditions.

This study uses Fuzzy - PID controller for AGC problem. For comparative analysis proportional-integralderivative (PID) controller has also been implemented. The results obtained show that the Fuzzy PID control scheme give good dynamic response with respect to conventional controllers.

The two-area interconnected thermal power system taken in this study. The model of the power system is as shown in Fig. 1. The control task is to minimize the system frequency deviation $\Delta f_{1}$ in area $1, \Delta f_{2}$ in area 2 and the deviation in the tie-line power flow $\Delta P_{12}$ between the two areas under the load disturbances $\Delta P_{L 1}$ and $\Delta P_{L 2}$ in the two areas. This is achieved conventionally with the help of controller which acts on ACE which is an input signal to the controller. Error input to the controller are respective area control errors (ACE) given by

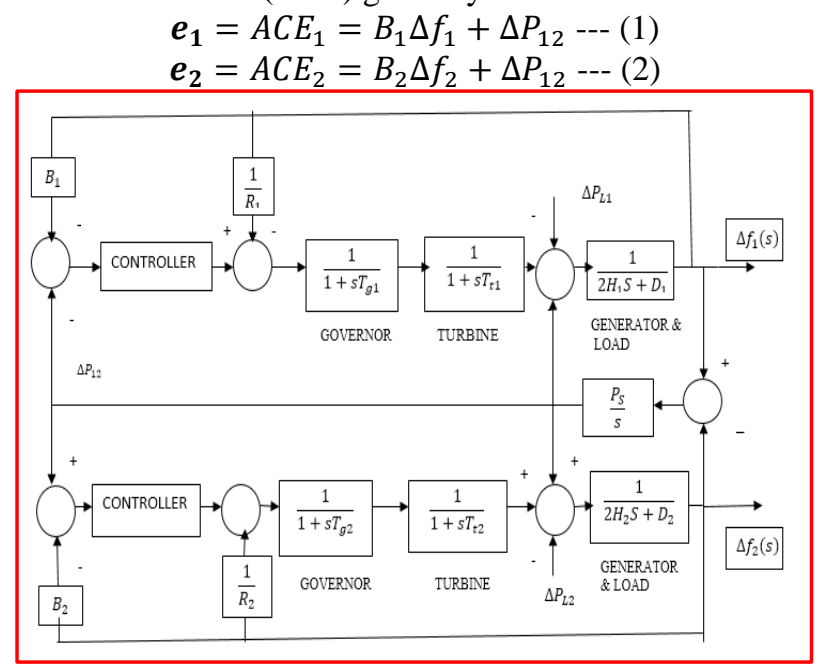

Fig:1.Transfer function model of two area inter connected power system

\section{PID CONTROLLER}

Proportional-Integral-Derivative (PID) control is the most common control tool in many industrial controlling applications because they can improve both transient response and steady state error of the system. The parameters of PID controller are proportional, integral and derivative which are varied to get optimal response shown in fig:2. 
In general, increasing the proportional gain will increase the speed of the control system response. However, if the proportional gain is too large, the process variable will begin to oscillate. The integral response will continually increase over time unless the error is zero, so the effect is to drive the Steady-State error to zero. Increasing the derivative time $\left(T_{d}\right)$ parameter will cause the control system to react more strongly to changes in the error term and will increase the speed of the overall control system response.

The transfer function of a PID controller has the following form

$$
G_{C}(s)=k_{p}+\frac{k_{i}}{s}+k_{d}(s)---(3)
$$

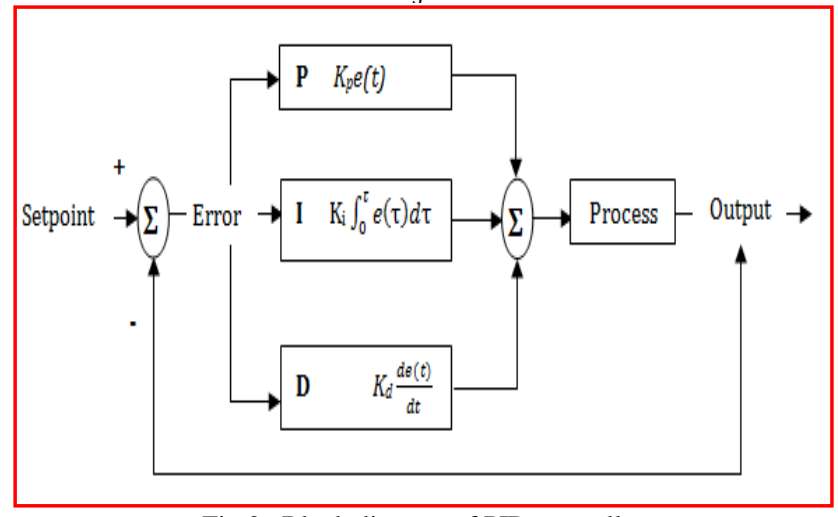

Fig:2. Block diagram of PID controller

Where, $k_{p}, k_{i}$, and $k_{d}$ are the proportional, integral, and derivative gains, respectively. In this work PID controller is designed and tuned using the method proposed in paper [4].

\section{FUZZY-PID CONTROLLER}

The parameters of a classical PID controller are fixed during operation. Consequently, such a controller is inefficient for control a system while the system is disturbed by surrounding environment and presence of nonlinearities in the system.

Fuzzy logic technology has the ability to give approximate recommended solution for unclear and complicated systems. It uses simple rules to explain behaviour of the system instead of using analytical equations, which makes it easy to implement. Fuzzy logic contains three primary elements fuzzification stage, rule base and defuzzification stage. In fuzzification stage crisp values of input variables are transformed into fuzzy membership values. Here are no general rules to select those variables, although typically the variables chosen are the states of the controlled system, their errors, error variation. Then, these membership values are processed within rule-base using conditional if-then statements. The output are summed and transformed input crisp values by using defuzzification procedure for appropriate control action.

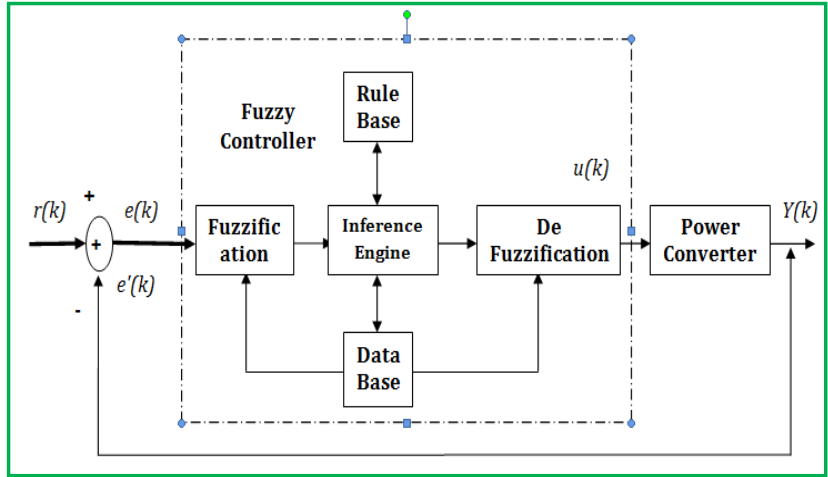

Fig:3. Block diagram of fuzzy logic controller

Conventional PID controllers are sensitive to variations in the system parameters, fuzzy controllers do not need precise information about the system variables in order to be effective. However, PID controllers are better able to control and minimize the steady state error of the system. To enhance the controller performance, hybridization of these two controller structures is done to utilize the advantages of both PID controller and fuzzy controller.

Like conventional PI or PD controllers, FLCs also have PI-type or PD-type and PID controllers. Essentially, a FLC design includes the type of FLC, the number and shape of membership functions (MFs), and the fuzzy rules. The block diagram of Fuzzy-PID controller in shown in Fig.4.

Fuzzy controller uses error (e) and derivative of error (de) as input signals. The input scaling factors are the tuneable parameters $K_{1}$ and $K_{2}$. The proportional, integral and derivative gains of fuzzy PID controller are represented by $K_{P}, K_{D}$ and $K_{I}$ respectively. Block diagram of fuzzy PID controller shown in fig: 4 .

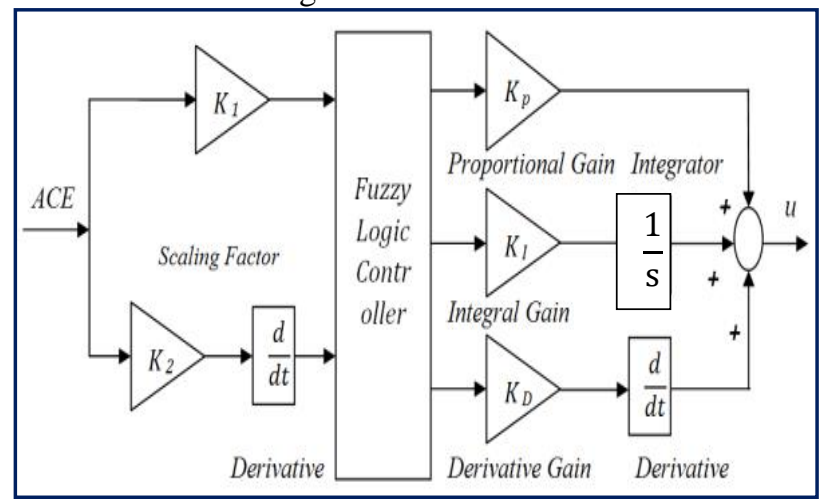

Fig:4. Block diagram of fuzzy PID controller

In this triangular membership functions are used with seven fuzzy linguistic variables such as NB (negative big), NM (negative medium), NS (negative small), Z (zero), PS (positive small), PM (positive medium) and PB (positive big) for both the inputs and the output. Membership functions for error, error derivative and FLC output are shown in Fig 5-7 respectively. Mamdani fuzzy interface engine is selected for this work. The FLC output is determined by using centre of gravity method of defuzzification. The two dimensional rule base for error, error derivative and FLC output is shown in the table1. 


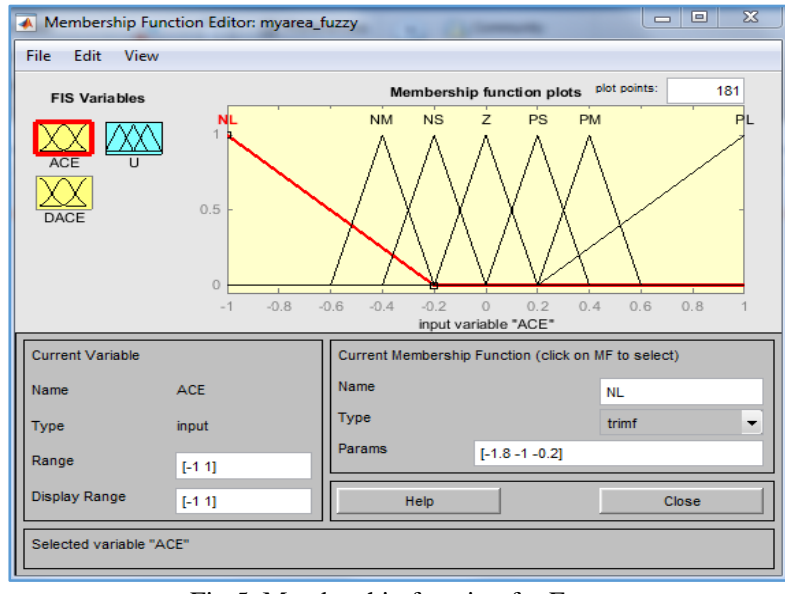

Fig:5. Membership function for Error

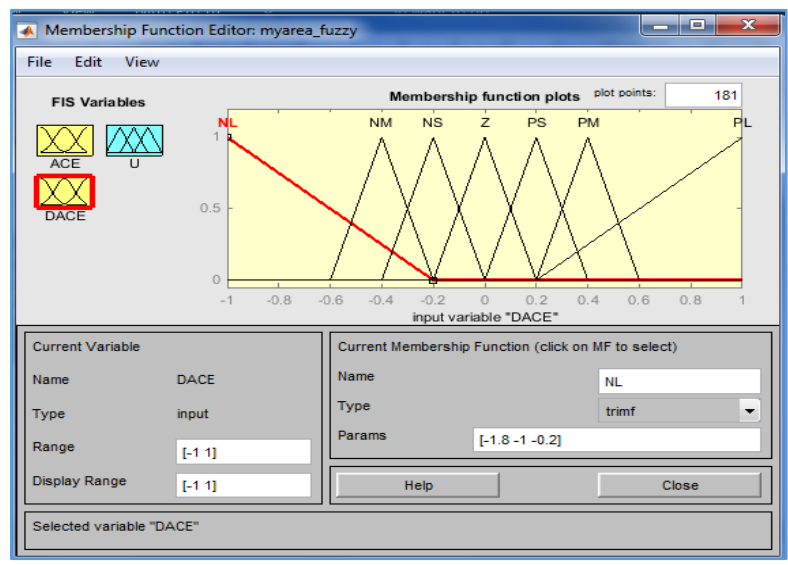

Fig:6. Membership function for Change in Error

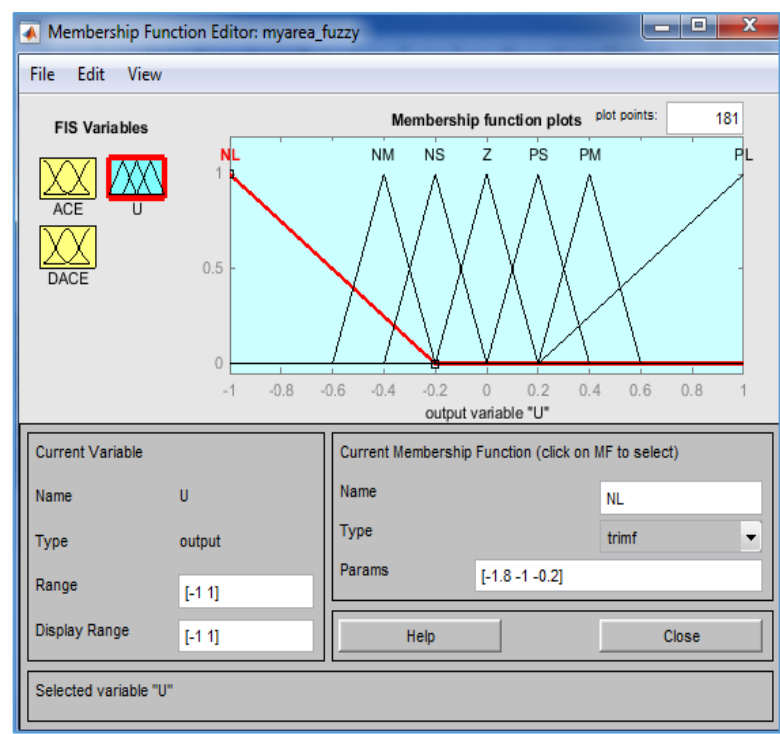

Fig:7. Membership function for FLC output

Table:1. Rule base for error, change in error, FLC output

\begin{tabular}{|c|c|c|c|c|c|c|c|c|}
\hline \multicolumn{9}{|c|}{ Error (e) } \\
\hline \multirow{8}{*}{$\begin{array}{l}\text { Chan } \\
\text { ge in } \\
\text { Error } \\
\text { (de) }\end{array}$} & & NB & NM & NS & $\mathrm{Z}$ & PS & PM & $\mathrm{PB}$ \\
\hline & NB & NB & NB & NB & NB & NM & NS & $\mathrm{Z}$ \\
\hline & NM & $\mathrm{NB}$ & NB & NB & $\mathrm{NM}$ & NS & $\mathrm{Z}$ & PS \\
\hline & $\mathrm{NS}$ & NB & NB & NM & NS & $\mathrm{Z}$ & PS & PM \\
\hline & $\mathrm{Z}$ & NB & NM & NS & $\mathrm{Z}$ & PS & PM & $\mathrm{PB}$ \\
\hline & PS & $\mathrm{NM}$ & NS & $\mathrm{Z}$ & PS & PM & PB & $\mathrm{PB}$ \\
\hline & $\mathrm{PM}$ & NS & $\mathrm{Z}$ & PS & PM & PB & PB & $\mathrm{PB}$ \\
\hline & $\mathrm{PB}$ & $\mathrm{Z}$ & PS & PM & PB & PB & PB & $\mathrm{PB}$ \\
\hline
\end{tabular}

\section{SIMULATION RESULTS AND COMPARATIVE}

\section{ANALYSIS}

(A). Simulation are performed on two area power system using PID and Fuzzy-PID controller under consideration. System parameters for two area power system for three cases is shown is shown in Appendix. The control parameters of PID controller proportional gain, integral gain and derivative gain are shown in Table 9. The frequency deviations of two area power system with PID Controller are shown from Fig.8 to Fig.13 for the case1, case 2 and case 3 respectively.

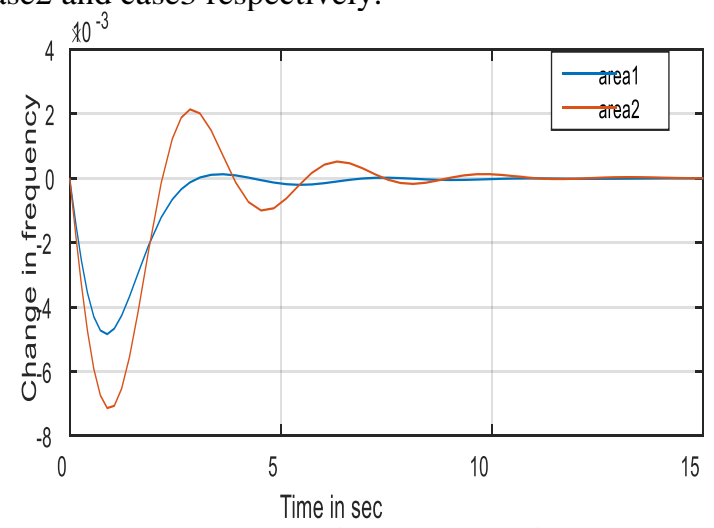

Fig:8. Frequency deviation of system in case 1 for $0.1 \mathrm{pu}$ load change

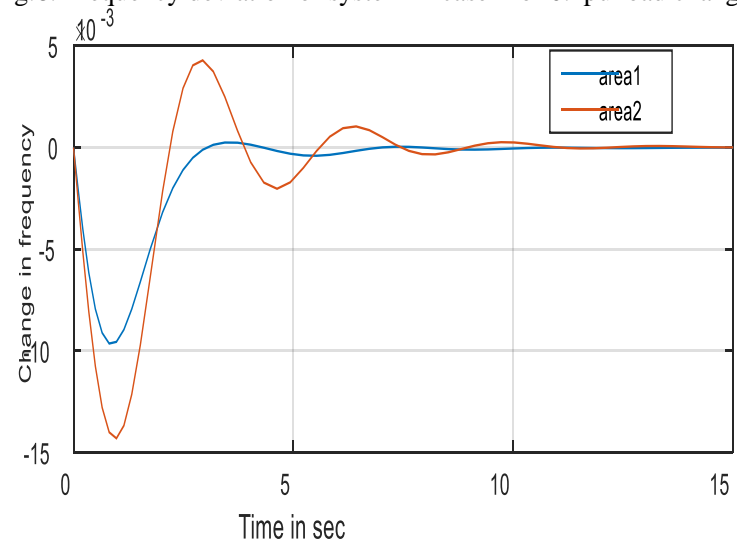

Fig:9. Frequency deviation of system in case 1 for $0.2 p u$ load change

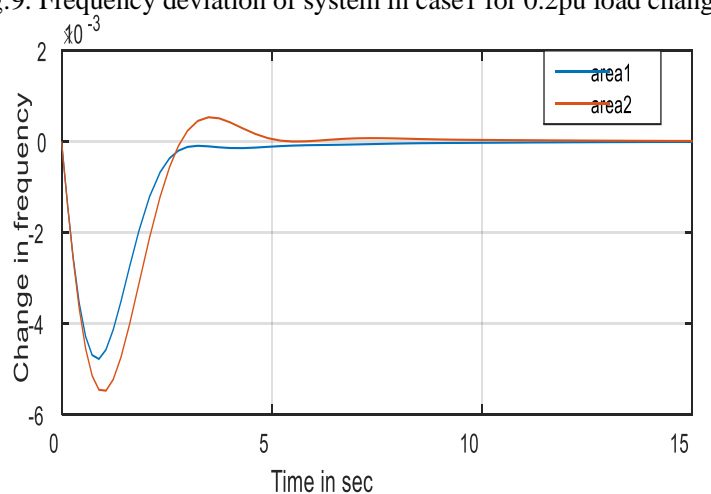

Fig:10. Frequency deviation of system in case 2 for 0.1 pu load change 


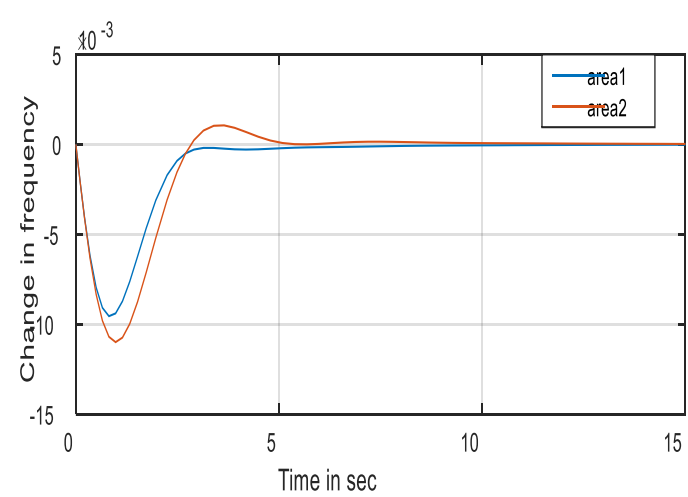

Fig:11. Frequency deviation of system in case 2 for $0.2 p u$ load change

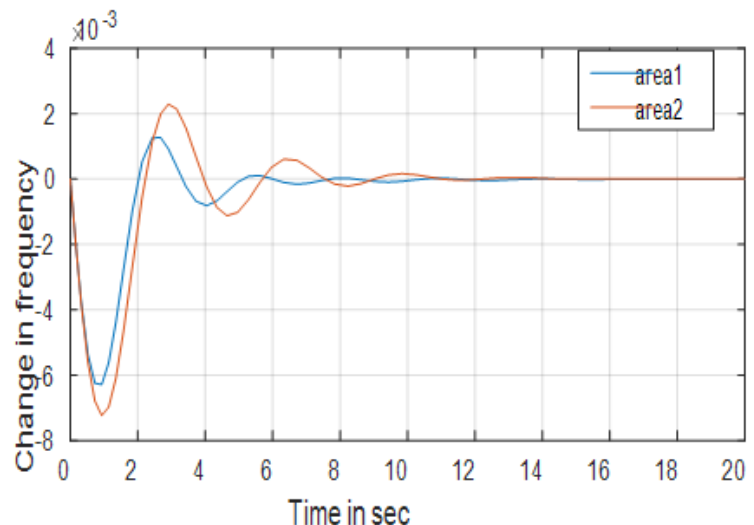

Fig: 12 . Frequency deviation of system in case 3 for 0.1 pu load change

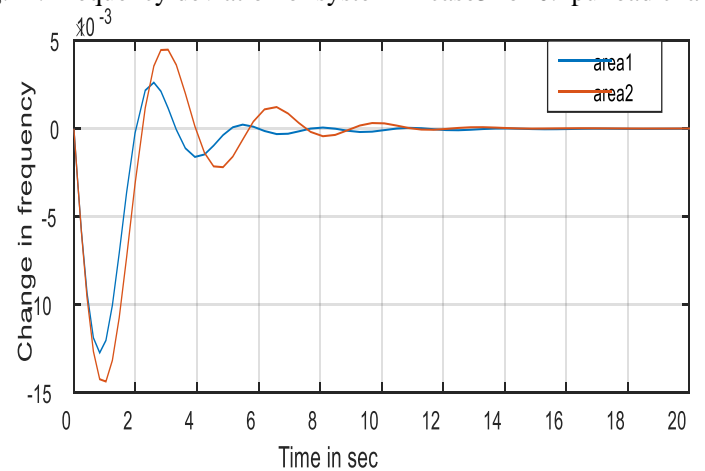

Fig:13 Frequency deviation of system in case 3 for 0.2 pu load change

(B). System parameters for two area power system for three cases is shown is shown in Appendix. The control parameters of Fuzzy- PID controller $K_{1}, K_{2}, K_{P}, K_{I}$, and $K_{d}$ are shown in table 10. The frequency deviations of two area power system with Fuzzy-PID controller are shown from Fig.14. to Fig.19.

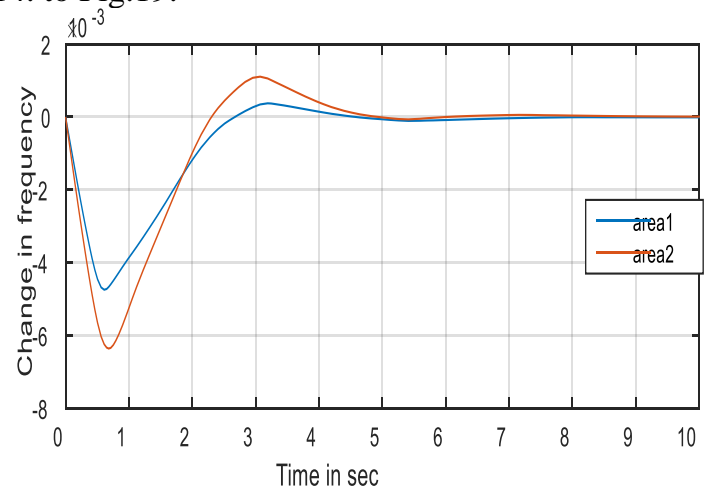

Fig:14. Frequency deviation of system in case 1 for 0.1 pu load change

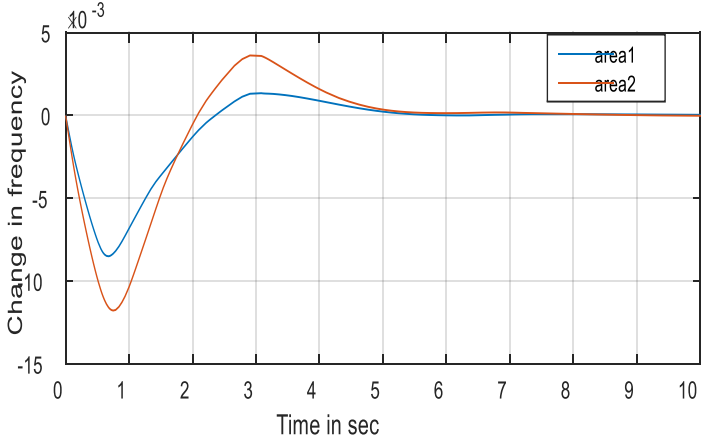

Fig:15. Frequency deviation of system in case 1 for $0.2 p u$ load change

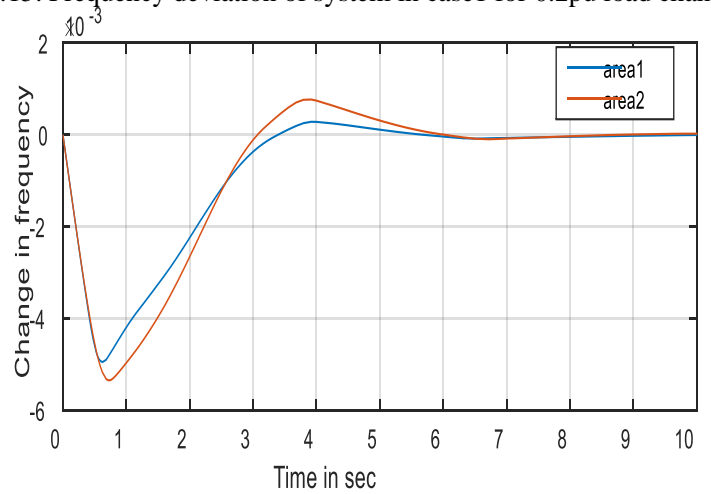

Fig:16. Frequency deviation of system in case 2 for 0.1 pu load change

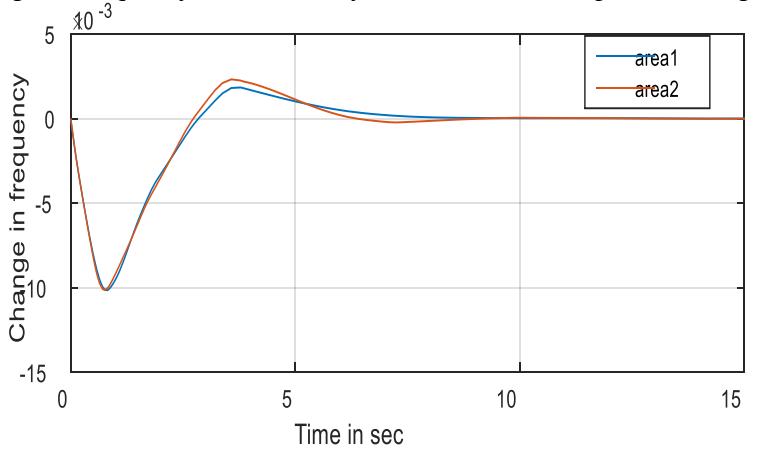

Fig:17. Frequency deviation of system in case2 for $0.2 p u$ load change

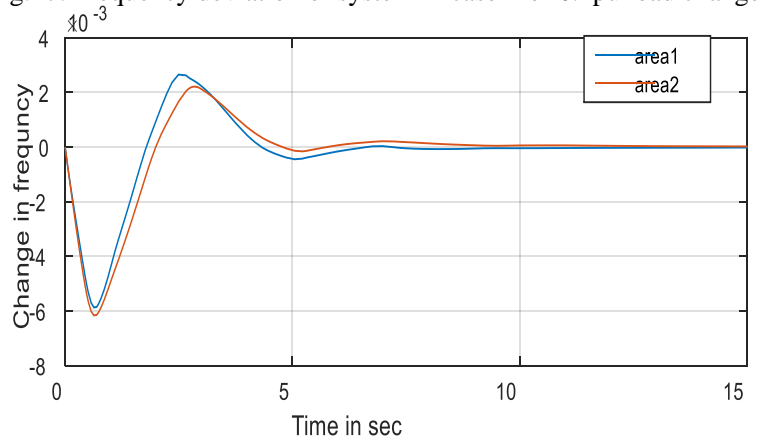

Fig: 18 . Frequency deviation of system in case 3 for 0.1 pu load change

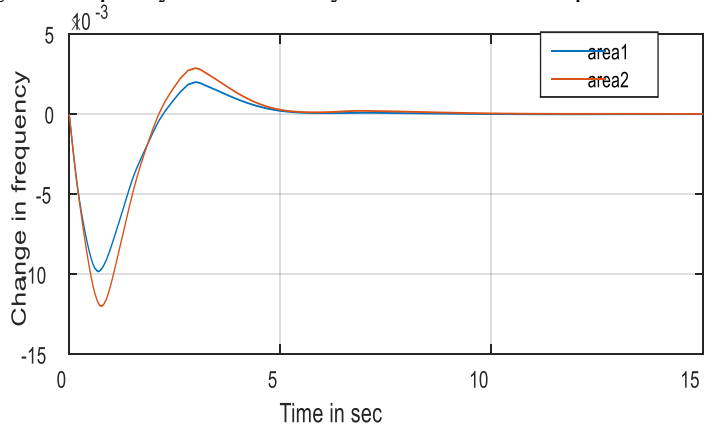

Fig:19. Frequency deviation of system in case 3 for $0.2 p u$ load change 
Table2: Different parameter response for AGC with PID

\begin{tabular}{|c|c|c|c|c|}
\hline \multicolumn{2}{|c|}{$\begin{array}{c}\text { AGC with PID } \\
\text { Load variation (10\%) }\end{array}$} & Case1 & Case2 & Case3 \\
\hline \multirow{2}{*}{ Area1 } & Settling time (sec) & 10 & 14 & 14 \\
\cline { 2 - 5 } & Maximum overshoot & $-4.5 \times 10^{-3}$ & $-4.7 \times 10^{-3}$ & $-6 \times 10^{-3}$ \\
\hline \multirow{2}{*}{ Area2 } & Settling time (sec) & 12 & 11 & 12 \\
\cline { 2 - 5 } & Maximum overshoot & $-7.2 \times 10^{-3}$ & $-5.5 \times 10^{-3}$ & $-7.5 \times 10^{-3}$ \\
\hline
\end{tabular}

Table3: Different parameter response for AGC with PID

\begin{tabular}{|c|c|c|c|c|}
\hline \multicolumn{2}{|c|}{$\begin{array}{c}\text { AGC with PID } \\
\text { Load variation (20\%) }\end{array}$} & Case1 & Case2 & Case3 \\
\hline \multirow{2}{*}{ Area1 } & Settling time (sec) & 11 & 14 & 13 \\
\cline { 2 - 5 } & Maximum overshoot & $-10 \times 10^{-3}$ & $-9.5 \times 10^{-3}$ & $-13 \times 10^{-3}$ \\
\hline \multirow{2}{*}{ Area2 } & Settling time (sec) & 12 & 12 & 14 \\
\cline { 2 - 5 } & Maximum overshoot & $-12 \times 10^{-3}$ & $-11 \times 10^{-3}$ & $-14 \times 10^{-3}$ \\
\hline
\end{tabular}

Table4: Different parameter response for AGC with Fuzzy- PID

\begin{tabular}{|c|c|c|c|c|}
\hline \multicolumn{2}{|c|}{$\begin{array}{c}\text { AGC with Fuzzy-PID } \\
\text { Load variation (10\%) }\end{array}$} & Case1 & Case2 & Case3 \\
\hline \multirow{3}{*}{ Area1 } & Settling time (sec) & 8 & 8 & 7 \\
\cline { 2 - 5 } & $\begin{array}{l}\text { Maximum } \\
\text { overshoot }\end{array}$ & $-4.5 \times 10^{-3}$ & $-4.7 \times 10^{-3}$ & $-6 \times 10^{-3}$ \\
\hline \multirow{3}{*}{ Area2 } & Settling time (sec) & 7 & 5 & 5 \\
\cline { 2 - 5 } & $\begin{array}{l}\text { Maximum } \\
\text { overshoot }\end{array}$ & $-6.2 \times 10^{-3}$ & $-5.5 \times 10^{-3}$ & $\begin{array}{c}6.5 \times 10^{-} \\
3\end{array}$ \\
\hline
\end{tabular}

Table5: Different parameter response for AGC with Fuzzy- PID

\begin{tabular}{|c|c|c|c|c|}
\hline \multicolumn{2}{|c|}{$\begin{array}{c}\text { AGC with Fuzzy-PID } \\
\text { Load variation (20\%) }\end{array}$} & Case1 & Case2 & Case3 \\
\hline \multirow{2}{*}{ Area1 } & Settling time (sec) & 5.5 & 5 & 5 \\
\cline { 2 - 5 } & Maximum overshoot & $-8.5 \times 10^{-3}$ & $-7 \times 10^{-3}$ & $-10 \times 10^{-3}$ \\
\hline \multirow{2}{*}{ Area2 } & Settling time (sec) & 7 & 6 & 6 \\
\cline { 2 - 5 } & Maximum overshoot & $-11 \times 10^{-3}$ & $-9 \times 10^{-3}$ & $-12 \times 10^{-3}$ \\
\hline
\end{tabular}

\section{CONCLUSION}

The frequency response analysis of two area AGC is analysed with PID and Fuzzy-PID controllers for different disturbances for different systems. It can be concluding that by using conventional PID controller number of oscillations, peak overshoot and settling time are high. To reduce oscillations, peak over shoot and settling time Fuzzy- PID controller is employed. The simulation results show that Fuzzy- PID controller gives better results in system response. The load frequency control is used to maintain zero steady state error. The reliable power supply has the characteristic of minimum frequency deviation and quality of power supply is determined by having constant frequency.

\section{Appendix:}

Table 6: Numerical values of two area power system model for case1

\begin{tabular}{|l|c|c|}
\hline \multirow{2}{*}{\multicolumn{1}{|c|}{ Parameters }} & \multicolumn{2}{c|}{ Case 1 } \\
\cline { 2 - 3 } & Area1(pu) & Area2(pu) \\
\hline Regulation & $R_{1}=0.05$ & $R_{2}=0.0625$ \\
\hline Load frequency sensitivity coefficient & $D_{1}=0.6$ & $D_{2}=0.09$ \\
\hline Inertia & $M_{1}=10$ & $M_{2}=8$ \\
\hline Base power & $1000 \mathrm{MVA}$ & $1000 \mathrm{MVA}$ \\
\hline Governor time constant & 0.2 & 0.3 \\
\hline Prime mover time constant & 0.5 & 0.6 \\
\hline Synchronizing power coefficient & 2 & \\
\hline
\end{tabular}

Table7: Numerical values of two area power system model for case2

\begin{tabular}{|l|c|c|}
\hline \multirow{2}{*}{\multicolumn{1}{|c|}{ Parameters }} & \multicolumn{2}{c|}{ Case 2 } \\
\cline { 2 - 3 } & Area1(pu) & Area2(pu) \\
\hline Regulation & $R_{1}=0.05$ & $R_{2}=0.05$ \\
\hline Load frequency sensitivity coefficient & $D_{1}=0.6$ & $D_{2}=0.6$ \\
\hline Inertia & $M_{1}=10$ & $M_{2}=10$ \\
\hline Base power & $1000 \mathrm{MVA}$ & $1000 \mathrm{MVA}$ \\
\hline Governor time constant & 0.2 & 0.2 \\
\hline Prime mover time constant & 0.5 & 0.5 \\
\hline Synchronizing power coefficient & 2 & \\
\hline
\end{tabular}

Table8: Numerical values of two area power system model for case3

Table8: Numerical values of two area power system model for case3
\begin{tabular}{|l|c|c|}
\hline \multirow{2}{*}{\multicolumn{1}{c|}{ Parameters }} & \multicolumn{2}{c|}{ Case 3 } \\
\cline { 2 - 3 } & Area1(pu) & Area2(pu) \\
\hline Regulation & $R_{1}=0.05$ & $R_{2}=0.05$ \\
\hline Load frequency sensitivity coefficient & $D_{1}=0.6$ & $D_{2}=0.6$ \\
\hline Inertia & $M_{1}=10$ & $M_{2}=10$ \\
\hline Base power & $1000 \mathrm{MVA}$ & $1000 \mathrm{MVA}$ \\
\hline Governor time constant & 0.2 & 0.2 \\
\hline Prime mover time constant & 0.5 & 0.5 \\
\hline Synchronizing power coefficient & 2 & \\
\hline
\end{tabular}

Table9: Different parameters of two area with PID controller

\begin{tabular}{|c|c|c|}
\hline Inter connected area & Optimum parameters & PID controller \\
\hline \multirow{4}{*}{ Area 1 } & $k_{I}$ & 0.7 \\
\cline { 2 - 3 } & $k_{p}$ & 0.25 \\
\cline { 2 - 3 } & $k_{D}$ & 0.33 \\
\hline \multirow{3}{*}{ Area 2 } & $k_{I}$ & 0.7 \\
\cline { 2 - 3 } & $k_{p}$ & 0.25 \\
\cline { 2 - 3 } & $k_{D}$ & 0.33 \\
\hline
\end{tabular}

Table10: Different parameters of two area with Fuzzy- PID controller

\begin{tabular}{|c|c|c|}
\hline Inter connected area & Optimum Parameters & PID controller \\
\hline \multirow{4}{*}{ Area 1 } & $k_{I}$ & 0.7 \\
\cline { 2 - 3 } & $k_{p}$ & 0.25 \\
\cline { 2 - 3 } & $k_{D}$ & 0.33 \\
\cline { 2 - 3 } & $k_{1}$ & 2.5 \\
\cline { 2 - 3 } & $k_{2}$ & 1 \\
\hline \multirow{5}{*}{ Area 2 } & $k_{I}$ & 0.7 \\
\cline { 2 - 3 } & $k_{p}$ & 0.25 \\
\cline { 2 - 3 } & $k_{D}$ & 0.33 \\
\cline { 2 - 3 } & $k_{1}$ & 2.5 \\
\cline { 2 - 3 } & $k_{2}$ & 1 \\
\hline
\end{tabular}

\section{REFERENCES}

[1] K.Jagatheesan, B.Anand, "AGC of Multi-Area Hydro-Thermal Power Systems with GRC Nonlinearity and Classical Controller", Journal of Global Information Management Volume 26 • Issue 3 • July-September 2018

[2] K.Jagatheesan, B.Anand, Nillanjan Dey, Amira S.Ashour, Cornel Barna, Valentina E.Balas, "Automatic Generation Control of an Interconnected Multi-Area Reheat Thermal Power Systems with Conventional Proportional Integral Controller Considering various Performance Indices" $11^{\text {th }}$ IEEE International Symposium on Applied Computational Intelligence and Informatics - May 1214, 2016 • Timişoara, Romania.

[3] Reena Kumari, Mr.Ram Avtar, "Automatic Generation Control of Multi Area Power System Using PID Controller". International Journal of Engineering Trends and Technology (IJETT). V4(5):1976-1980 May 2013. ISSN:2231-5381. 
[4] M. Nagendra, M.S.Krishnarayalu, (Sep 2012), "PID controller tuning Simulink for Multi Area Power Systems" International Journal of Engineering Research \& Technology, vol. 1 Issue 7.

[5] RishabhVerma, Shalini PalSathans, "Intelligent Automatic Generation Control of Two-Area Hydrothermal Power System using ANN and Fuzzy Logic" 2013 International Conference on Communication Systems and Network Technologies.

[6] Sathans, A. Swarup, "Intelligent Automatic Generation Control of Two Area Interconnected Power System using Hybrid NeuroFuzzy Controller," International Journal of Electrical and Electronics Engineering, vol. 5, pp. 1448-1453, Winter 2011.

[7] C.Srinivasa Rao, "Design of Artificial Intelligent Controller for Automatic Generation Control of Two Area Hydrothermal System," International Journal of Electrical and Computer Engineering (IJECE), vol. 2, No.2, pp. 183-190, April 2012.

[8] Vijay Kumar Singh, Ratna Dahiya, "Automatic Generation Control System Using PI and FIS Controller.", Proceeding of 2018 IEEE International Conference on Current Trends Toward Converging Technologies, Coimbatore, India.

[9] PuranLal, Mainak Roy, "Two Area Control of AGC using PI \& PID Control by Fuzzy Logic", International Journal of Advance Research in Science and Engineering, IJARSE, Vol. No.4, Issue 03, March 2015 ISSN-2319-8354(E).

[10] VivekNath, D.K.Sambariya, "Analysis of AGC and AVR for Single Area and Double Area Power System Using Fuzzy Logic Control", International Journal of Advanced Research in Electrical, Electronics and Instrumentation Engineering, 10.15662/ijareeie. 2015.040707. 